\title{
Importance of controlling church outbreaks during the coronavirus disease 2019 pandemic: an epidemiological study
}

\author{
Cho Ryok Kang ${ }^{1}$, Sae Kyung Joo ${ }^{2}$, Ho Jun Kim³ ${ }^{3}$, Yoojin Park ${ }^{4}$, In Sil Huh ${ }^{4}$, Young Sin Moon ${ }^{5}$, \\ Kwang Hwan Oh${ }^{5}$, Hyon Jeen Ham ${ }^{1}$, Jin Kyeong Han ${ }^{1}$, Jung II Kim ${ }^{1}$, Jin Yong Lee ${ }^{6,7,8^{*}}$, Baeg Ju Na ${ }^{9, *}$ \\ and Seoul Metropolitan Government COVID-19 Rapid Response Team (SCoRR Team) \\ ${ }^{1}$ Disease Control and Prevention Division, Seoul Metropolitan Government, Seoul, Korea, \\ ${ }^{2}$ Department of Internal Medicine, Seoul Metropolitan Government-Seoul National University Boramae Medical Centre, \\ Seoul, Korea \\ ${ }^{3}$ Department of Family Medicine, Seoul Metropolitan Government-Seoul National University Boramae Medical Centre, \\ Seoul, Korea \\ ${ }^{4}$ Seoul Centre for Infectious Disease Control and Prevention, Seoul, Korea \\ ${ }^{5}$ Guro-gu Public Health Centre, Seoul, Korea \\ ${ }^{6}$ Department of Health Policy and Management, Seoul National University College of Medicine, Seoul, Korea \\ ${ }^{7}$ Public Healthcare Center, Seoul National University Hospital, Seoul, Korea \\ ${ }^{8}$ Research Institute, Health Insurance Review and Assessment Service, Wonju, Korea \\ ${ }^{9}$ Graduate School of Urban Public Health, University of Seoul, Korea
}

\section{Correspondence to Jin Yong Lee}

Department of Health Policy and Management, Seoul National University College of Medicine 101 Daehak-ro, Jongno-gu, Seoul 03080, Republic of Korea

E-mail: jylee2000@gmail.com

\section{Baeg Ju Na}

Graduate School of Urban Public Health, University of Seoul

163 Seoulsiripdaero, Dongdaemun-gu, Seoul 02504, Republic of Korea

E-mail: baegju.na@gmail.com 


\begin{abstract}
An epidemiological investigation was conducted of a coronavirus disease 2019 (COVID-19) outbreak related to a church in Seoul. Basic epidemiological data were collected using a standardized form. Among 48 confirmed cases of COVID-19 related to 'Church X', transmission of SARS-CoV-2 was identified among church staff members and their families, and church members and their families and colleagues. Two major inter-related clusters were identified that included 12 staff members and 10 church members (including one staff member). It is important to implement rapid case finding and contact tracing to prevent snowballing outbreaks from the church to the community. In addition, social distancing could be a major measure to prevent the spread of COVID-19 within churches and the community.
\end{abstract}

Keywords: COVID-19; SARS-CoV-2; outbreak; epidemiology; investigation; church. 


\section{Introduction}

Many countries and cities are currently affected by coronavirus disease 2019 (COVID-19) and are devoting all their efforts to containing outbreaks in facilities where large groups of people gather [1]. Religious gatherings, in particular, make it very easy to spread SARS-CoV-2 infection due to the lack of wearing face masks use during prayers and hymns, and the close proximity of many church members within an enclosed space [2]. In addition, church members who become infected may spread SARS-CoV-2 infection in the community.

In France, between February 17 and 21, 2020, an event of the Christian Open Door evangelical megachurch was held and attended by over 2,000 church members. After the event, infected individuals scattered all over France, and 2,500 COVID-19 cases related to this church event were confirmed [3]. In Korea, the 31st COVID-19 patient was reported on February 18, 2020 [4]. This patient was linked to the Shincheonji Daegu Church, and over 5,000 COVID-19 cases related to this church were subsequently confirmed, accounting for half of the total confirmed cases in Korea to date [5]. Another outbreak occurred in a megachurch ('Church X') located in K-gu in Seoul, Korea. Because of the increasing number of outbreaks in the community, the Seoul Metropolitan Government emphasized the importance of practicing social distancing in churches and avoiding religious gatherings, and since March 2, 2020 has been conducting on-site inspections to ensure social distancing. This church converted all worship services to online services from March 6, and more than 150 members of the church gathered for preparation of the online worship service on Sunday. Many members of the church lived in K-gu and other districts such as J-gu, L-gu, M-gu, and other cities including P-si of Gyeonggi-do. The first confirmed case was in a man who worked as a guard at the 'Church $\mathrm{X}$ ' housing compound in M-gu. He had no travel history or known contact with any confirmed patients or outbreaks. His SARS-CoV-2 infection was confirmed on March 25 after initial symptoms of muscle pain and chills began on March 17. On March 27, the outbreak was recognized after further cases were discovered among the guard's family members, fellow guards, and church staff of the church, confirmed by testing positive. Therefore, an epidemiological investigation was initiated under the supervision of the Seoul Metropolitan Government COVID-19 Rapid Response Team (SCoRR Team).

This outbreak is a representative example of the spread of COVID-19 in the community through religious gatherings. The purpose of this report is to describe the epidemiology of the COVID-19 outbreak related to 'Church X' and to discuss effective strategies to control COVID-19 outbreaks within the church and community. 


\section{Materials and Methods}

\subsection{Case definition}

A patient under investigation (PUI) was defined as a person associated with 'Church X', and a suspected case was defined as a person who had been in contact with a confirmed case. A confirmed case was defined as a PUI or suspected case with a positive SARS-CoV-2 laboratory test using a real-time reverse-transcription-polymerase-chain-reaction (RT-PCR) assay.

\subsection{Case findings}

Considering that the source of the infection in the index case was unknown and that the guard belonged to a 'megachurch', mass COVID-19 testing was conducted by reporting the potential outbreak to PUIs. A total of 433 people were tested and quarantined, including 204 attendees of the online worship on March 22, 75 full-time workers, 79 non-full-time workers, 34 orchestra members, and 81 visitors to S-gun on March 5. Since the first confirmed case worked as a guard post of houses of the church, 20 residents of the houses were also classified as PUls and tested. The reason why the visitors to S-gun on March 5 required testing was that two local members of the church in S-gun were also confirmed as SARS-CoV-2 positive. The participants of the online worship service on March 22 were staff and church members who had attended the online service. Individuals who were classified as contacts, such as family members or colleagues of a confirmed case, were reported as suspected cases, tested, and quarantined for 14 days.

K-gu Public Health Centre installed and operated two screening clinics at the church from March 27 to March 30 for active case finding. In addition, 5,500 worshippers who visited the church from the first week of February through March received a text message to notify them of the outbreak and to recommend that they undergo testing if they had any symptoms. As additional confirmed cases were identified among the staff and church members, the church was ordered to close on March 27. Confirmed cases included staff of the church, S-gun visitors, online worship attendees and tenants of houses owned by the church. Additionally, two confirmed cases who were sisters and attended the online worship worked at $\mathrm{H}$ call center located in L-gu. It was then assumed that the call center was vulnerable to the spread of COVID-19 [6]. Thus, screening tests and quarantine measures were performed for all 67 employees of the call center, and additional confirmed cases were identified.

\subsection{Epidemiological investigation}

The public health center where the index case was diagnosed carried out a basic epidemiological investigation using a standardized epidemiologic investigation form. This form is included information on demographic characteristics, symptoms, underlying diseases, suspected transmission route, and use of group facilities. The public health center conducted contact tracing of contacts dating back to one day before the onset of symptoms, and checked the credit card payment history, geographical positioning service (GPS), drug utilization review (DUR), and closed-circuit television (CCTV) of individuals with confirmed SARS-CoV-2 infection to determine their movements in the community. 
The SCoRR Team conducted an on-site epidemiological investigation with the K-gu Office. Most of the confirmed cases were diagnosed at the screening clinic established by the K-gu Public Health Centre, but some cases were diagnosed at the screening clinic of another public health center in the residential district. As several public health centers conducted the basic epidemiological investigation, public health officers of the SCoRR team conducted additional in-depth investigations to identify the transmission route and epidemiological associations among the confirmed patients.

\subsection{Data collection and analysis}

The analysis used the basic epidemiological investigation data collected using the standardized form, and in-depth epidemiological investigation data. The results were presented as frequencies and percentages for categorical variables, and as medians and ranges for continuous variables.

\subsection{Ethics approval}

This study was reviewed and approved by the Institutional Review Board (IRB) of the Seoul Metropolitan GovernmentSeoul National University Boramae Medical Center (IRB No: 07 - 2020 - 12 / 043).

\section{Results}

\subsection{Epidemiology of the confirmed cases}

Table 1 shows the epidemiology of the confirmed cases of the COVID-19 outbreak related to 'Church X'. The median age of the 48 confirmed cases was 52 years and 33.3\% were male. The majority of the cases were diagnosed and investigated by the K-gu Public Health Centre (22 cases) and J-gu Public Health Centre (12 cases). Thirty-eight confirmed cases lived in six districts of Seoul, seven cases lived in two cities of Gyeonggi-do, two cases lived in Incheon, and one case lived in Jeollanam-do. Of the confirmed cases, 11 were asymptomatic and two cases were uncertain about the onset of symptoms because they had underlying diseases. Among 35 symptomatic patients, major initial symptoms were chills $(25.7 \%)$, muscle pain $(20 \%)$, cough $(20 \%)$, sputum production $(14.3 \%)$, sensation of warmth $(14.3 \%)$, headache $(11.4 \%)$, and sore throat $(11.4 \%)$. 
<Table 1> Epidemiology of 48 confirmed cases of COVID-19 from the 'Church X' outbreak

\begin{tabular}{|c|c|}
\hline Characteristic & All patients $(\mathrm{N}=48)$ \\
\hline \multicolumn{2}{|l|}{ Demographics } \\
\hline Median age (range), years & $52(14-91)$ \\
\hline Male, no. (\%) & $16(33.3)$ \\
\hline \multicolumn{2}{|l|}{ Residential district } \\
\hline Seoul, no. (\%) & $38(79.1)$ \\
\hline J-gu, no. (\%) & $13(27.1)$ \\
\hline K-gu, no. (\%) & $10(20.8)$ \\
\hline L-gu, no. (\%) & $7(14.5)$ \\
\hline M-gu, no. (\%) & $6(12.5)$ \\
\hline L-gu, no. (\%) & $1(2.1)$ \\
\hline O-gu, no. (\%) & $1(2.1)$ \\
\hline Gyeonggi-do, no. (\%) & $7(14.6)$ \\
\hline P-si, no. (\%) & $6(12.5)$ \\
\hline Q-si, no. (\%) & $1(2.1)$ \\
\hline Incheon, no. (\%) & $2(4.2)$ \\
\hline R-gu, no. (\%) & $2(4.2)$ \\
\hline Jeollanam-do, no. (\%) & $1(2.1)$ \\
\hline S-gun, no. (\%) & $1(2.1)$ \\
\hline \multicolumn{2}{|l|}{ Symptoms } \\
\hline Yes, no. (\%) & 35 (72.9) \\
\hline No, no. (\%) & $11(22.9)$ \\
\hline Uncertain, no. (\%) & $2(4.2)$ \\
\hline
\end{tabular}

\subsection{Epidemic curves based on symptom-onset-date and diagnosis-date}

Figure 1 shows how the 'Church X' COVID-19 outbreak progressed with the dynamic association between church staff and their families, families of staff and church members, and church members and their families and colleagues. After a series of tests were conducted in accordance with the active case finding strategy from March 27, asymptomatic confirmed cases among staff and their families, and church members and their colleagues ( $\mathrm{H}$ call center) were identified.

Figure $1 \mathrm{~A}$ shows the epidemic curve of 35 symptomatic cases based on the symptom-onset-date. Figure $1 \mathrm{~B}$ shows the epidemic curve of the 11 asymptomatic cases and two cases with an uncertain date of onset, using the diagnosis date as the date of onset.

In this study, we categorized the confirmed cases into four groups: cases who were staff of the church (group A), those who were family members of staff (group B), those who were church members (group C), and those who were family members or colleagues of church members (group D). The numbers in the boxes indicate the order of diagnosis. 

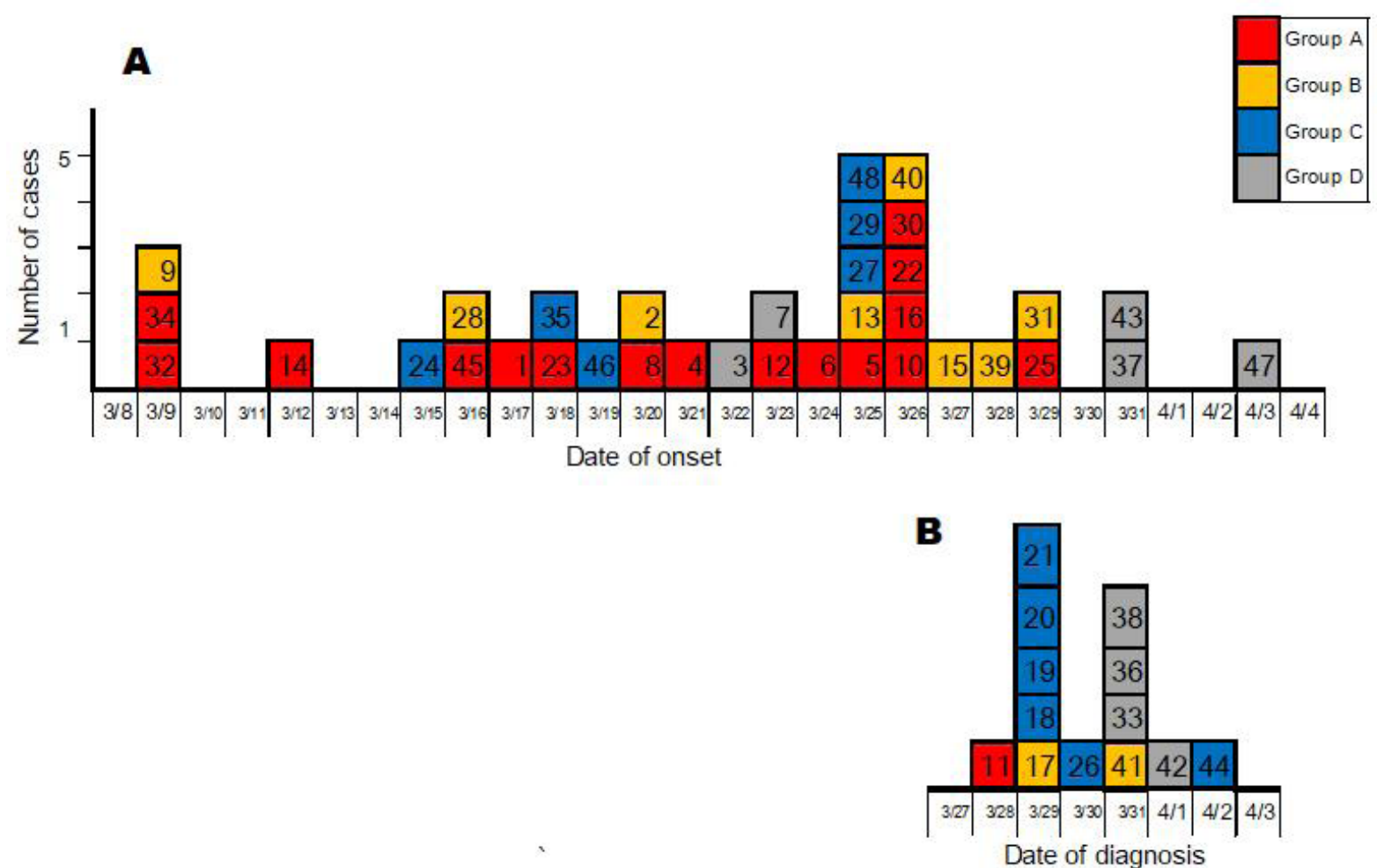

<Figure 1> Epidemic curves of 48 confirmed cases of COVID-19 from the 'Church X' outbreak. (A) Epidemic curve of symptomatic cases. (B) Epidemic curve of asymptomatic cases or cases with uncertain date of onset. The numbers in the box indicate the order of diagnosis. The staff of the church is grouped in red (Group A); Family members of staff are grouped in yellow (Group B); Members of the church are grouped in blue (Group C); Family members and colleagues of members of the church are grouped in grey (Group D).

\subsection{Epidemiological connections}

Figure 2 shows the epidemiological connections between the confirmed cases. Each case was assigned a number indicating the order of diagnosis and grouped by color-coding. Among the confirmed cases, there were a total of six visitors to S-gun on March 5, and four of them (Cases 9, 24, 32, and 34) had the first symptoms within 14 days of March 5. One cluster was identified in which the husband (Case 45) of Case 9 was connected with 11 church staff members, and another cluster of eight church members was connected with case 28 who was associated with cases 9 and 34 . That is, it was identified that these two major clusters including 12 staff members and 10 church members (including one staff) were related to each other. Case 45 infected the first confirmed case (Case 1) who worked as a guard of houses belonging to the church, and additional cases amongst his family members and their colleagues were confirmed. As staff working in the same office as Case 45 were infected (Cases 6, 8, 10, 16, and 23), other office workers entering the office were also infected (Cases 11, 14, and 30), and then their family members were infected. Through Case 28, seven cases (Cases 12, 22, 26, 27, 44, 46, and 48) among eight people (one pastor, seven church members) who visited the 
church member's house on March 17 were confirmed to be infected. All guests, including Case 28, sat very close to one another, talked to each other, prayed, and ate. In addition, Case 29 who attended the meal meeting with five already exposed cases (Cases 12, 22, 26, 27, and 46) on March 19 was confirmed, and all family members of Case 29 (Cases 36, 37, and 38) were infected. Four cases were not associated with any other cases (Cases 18, 19, 20, and 21) were family members of the siblings who worked at the call center, and although they were active church members, they did not interact with other church members. Even though online worship started on March 6, they attended the worship every Sunday and were confirmed to be infected during testing carried out for active case finding. Three additional cases were confirmed among the 69 employees of the $\mathrm{H}$ call center where two sisters (Cases 20 and 21) worked, bring the total number of cases at the $\mathrm{H}$ call center to five (attack rate: $7.2 \%$ ). Among the 48 confirmed cases, a total of 15 cases related to 10 confirmed cases were presumed to have become infected with SARS-CoV-2 through household transmission.

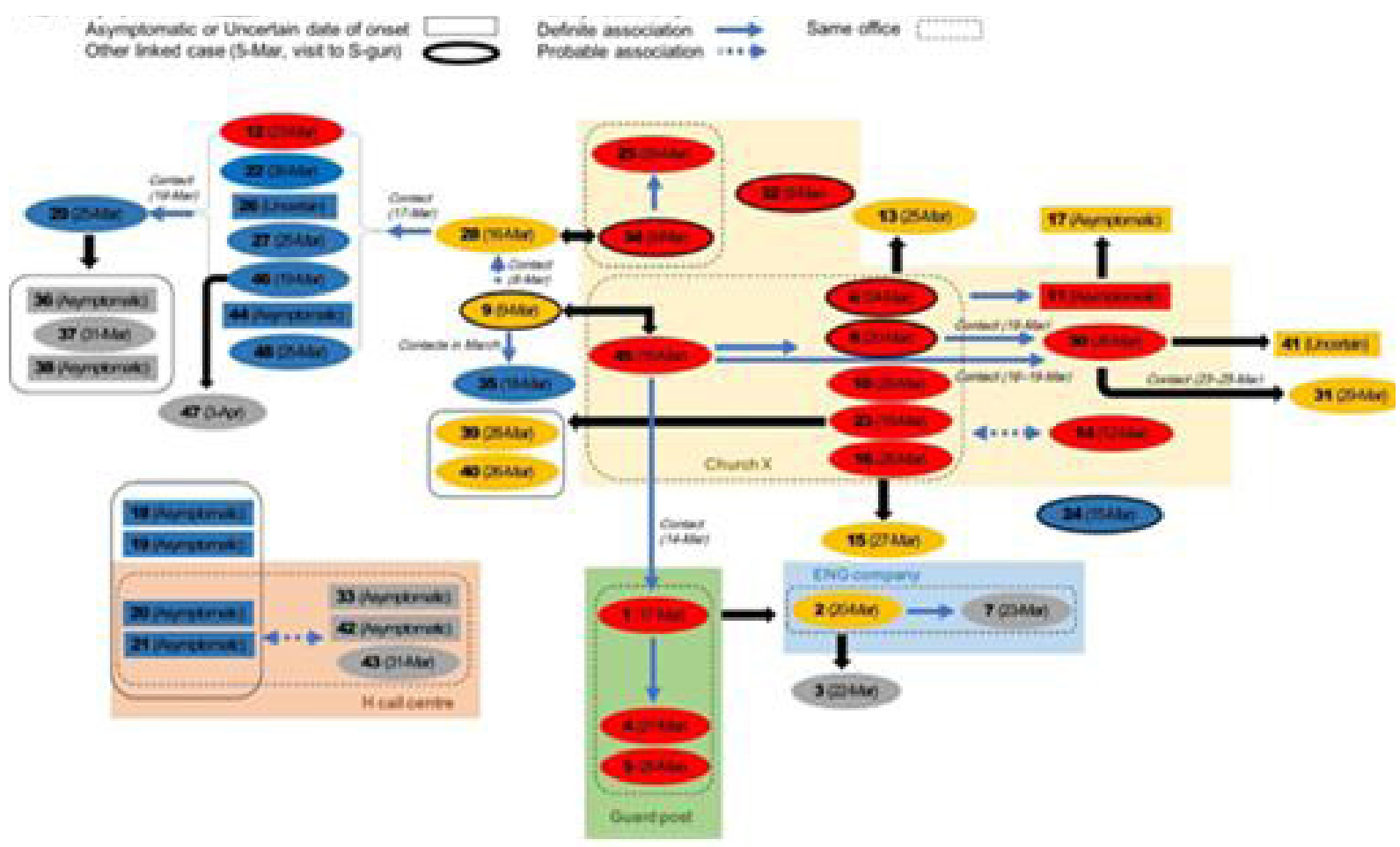

<Figure 2> Epidemiological associations of COVID-19 cases from the 'Church X' outbreak. The numbers indicate the order of diagnosis. The dates in parentheses indicate the symptom-onset-date. Staff members of the church are grouped in red (Group A); Family members of the staff are grouped in yellow (Group B); Members of the church are grouped in blue (Group C); Family members and colleagues of the members of the church are grouped in grey (Group D). 


\section{Discussion}

The findings of this study suggest the possibility that there may be undiagnosed COVID-19 cases in the community for the following reasons: First, it was possible to estimate the likelihood of COVID-19 exposure during the S-gun visit. The confirmed cases with an early symptom onset date were related to a history of visiting the church in S-gun on March 5. Particularly, Case 24 who lived in Incheon did not visit the church and meet with other church members after visiting S-gun on March 5 because online worship began on March 6. Case 14 who had early symptom onset lived with her mother-in-law (negative result on March 27) who showed symptoms after visiting S-gun on March 5. Meanwhile, two church members in S-gun were also confirmed after mid-March, although no epidemiological connection with visitors from Seoul was identified. Second, four confirmed cases (Cases 18, 19, 20, and 21) who were family members were not epidemiologically associated with any other cases related to the church. Additionally, three confirmed cases were identified in the $\mathrm{H}$ call center; however, it was difficult to determine the index case in the call center. Asymptomatic or mild patients may have remained undetected [7], and may have transmitted the virus in clusters [8]. Even in this outbreak, an asymptomatic patient (case 11) infected his family member (Case 17), and Case 45 infected a staff member of the church (Case 1) whom he met 2 days before initial symptoms occurred. Because of the possibility of undiagnosed cases in the community, containment strategies to prevent community transmission should be implemented. Seoul Metropolitan Government has successfully contained COVID-19 through testing on a massive scale, prompt contact tracing, and quarantine [9].

The COVID-19 epidemic related to 'Church X' involved two major clusters of 12 church staff members and 10 church members, and the transmission occurred to family members and colleagues of persons in these clusters. This outbreak showed that the associations among church members provide frequent opportunities for close contact, which can lead to snowballing outbreaks in the community. As can be seen in this outbreak example, members of the megachurch lived in various districts. This situation can lead to the widespread transmission of COVID-19 within the community. However, it was possible to end the epidemic through active case finding and quarantine. In terms of the easy spread to the community, through inter-personal infection in the church where close contacts occurred, churches should be considered as a very important management target for blocking the spread of COVID-19.

There are various contacts through religious gatherings or small group meetings of the church. Therefore, it is necessary to prevent snowballing outbreaks related to the church based on rapid case finding and contact tracing. Since the transmission route of the confirmed cases must be identified to understand the epidemiological connections, it is necessary to conduct in-depth interviews to identify the epidemiological association among confirmed cases. This is the basis for judging whether to implement appropriate measures for preventing the spread of COVID-19. Moreover, it is necessary to secure a list of attendees of religious gatherings or small group meetings for rapid case finding and contact tracing. In the course of this epidemiological investigation, a list of visiting church members of the pastor (Case 12) was obtained and they were tested to find cases. As a result, three additional cases were confirmed. GPS tracking of church members identified the contact history with a key person (Case 28) on March 17, and it was possible to find 
the epidemiological connection among confirmed cases. Thus, it is also necessary to use auxiliary means (such as GPS and (CTV) to verify statements related to staying at home or attending a gathering or meeting.

Social distancing (or physical distancing) is a behavioral change that increases the space between people to block the spread of infectious diseases [10], and it is considered the key measure to decrease the chance of spreading COVID-19 [11]. Social distancing is considered as part of a community non-pharmaceutical intervention (NPI) strategy [12], and restriction of mass gatherings and changes in the workplace, as well as facility closures, are considered effective measures of social distancing [13-14]. This epidemic related to the church could have been reduced by converting field worship to online worship as part of social distancing. This would have resulted in a result that contrasts sharply with the case of the Shincheonji Church, which had over 5,000 confirmed cases [5]. In addition, at $\mathrm{H}$ call center where two out of four family members worked, it may have been possible to limit infection to only three cases by wearing a face mask during work, maintaining a distance of 2 meters between seats, and fever monitoring measures. After a massive outbreak in the call center that occurred before [6], As Seoul Metropolitan Government made efforts to conduct on-site inspections to ensure social distancing in call centers, mostly all call centers tried to improve the environment of the workplace by practicing social distancing. As a result, five out of 69 employees of $\mathrm{H}$ call center were diagnosed (attack rate: $7.2 \%$ ), and this result contrasts with that of the call center where 94 out of 216 employees (43.5\%) on one floor were confirmed [6]. To date, there is no vaccine or effective target treatment, so measures for social distancing should be continuously considered in various settings to prevent the spread of COVID-19 in the community.

\section{Conclusions}

The COVID-19 outbreak of 'Church X' progressed with the dynamic association between church staff and their families, families of staff and church members, and family members and colleagues of church members. It was identified that two major clusters occurred in which 12 staff members and 10 church members (including one staff) were related to each other. This study suggested that it is important to implement rapid case finding and contact tracing to prevent a snowballing outbreak from the church into the community. In addition, social distancing could be a major measure to prevent the spread of COVID-19 within the church and the community.

Author Contributions: C.R.K. contributed to study design, analyzed the data, interpreted the data, drafted and amended the manuscript. S.K.J., H.J.K., Y.P. and I.S.H. contributed to the analysis of the data and amended the manuscript. Y.S.M., K.H.O., H.J.H., J.K.H., and J.I.K. participated and amended the manuscript, B.J.N. and J.Y.L. contributed to study design, supervised the research, data interpretation, and amended the manuscript. All authors have read and agreed to the published version of the manuscript.

Funding: This research received no external funding.

Conflicts of Interest: The authors declare no conflict of interest. 


\section{References}

1. Baniamin HM, Rahman M, Hasan MT. The COVID-19 pandemic: Why are some countries more successful than others? (14 Apr 2020). http://dx.doi.org/10.2139/ssrn.3575251 (accessed 17 May 2020).

2. Kang YJ. Characteristics of COVID-19 infection in Korea from the mass infection perspective. J Preventive Med Public Health 2020. https://doi.org/10.3961/jpmph.20.072.

3. Evangelical service in eastern France is center of new virus outbreak (4 Mar 2020). https://www.reuters.com/article/us-health-coronavirus-france-church/evangelical-service-in-eastern-france-is-centerof-new-virus-outbreak-idUSKBN20R1Q4 (accessed 17 May 2020).

4. Yoo JH, Chung MS, Kim JY, et al. Report on the epidemiological features of coronavirus disease 2019 (COVID-19) outbreak in the Republic of Korea from January 19 to March 2, 2020. J Korean Med Sci 2020;35:e112.

5. Korea Centers for Disease Control and Prevention. Coronavirus Infection-19 Domestic Outbreaks (7 Apr 2020). http://ncov.mohw.go.kr/tcmBoardView.do?brdld=\&brdGubun=\&dataGubun=\&ncvContSeq=353965\&contSeq_id= \&gubun=ALL (accessed 17 May 2020).

6. Park SY, Kim YM, et al. Coronavirus disease outbreak in call center, South Korea. Emerg Infect Dis 2020;26. http://doi:10.3201/eid2608.201274.

7. Her M. How is COVID-19 affecting South Korea? What is our current strategy? Disaster Med and Public Health Prep 2020;1-3. http://doi:10.1017/dmp.2020.69.

8. Bai Y, Yao L, Wei T, et al. Presumed asymptomatic carrier transmission of COVID-19. JAMA 2020;323:1406-7.

9. How South Korea Flattened the Curve. The New York Times (23 Mar 2020). Available at: https://www.nytimes.com/2020/03/23/world/asia/coronavirus-south-korea-flatten-curve.html (accessed 17 May 2020).

10. Sen-Crowe B, McKenney M, Elkbuli A. Social distancing during the COVID-19 pandemic: Staying home, save lives. Am J Emerg Med 2020. https://doi:10.1016/j.ajem.2020.03.063.

11. Centers for Disease Control and Prevention. Social distancing, quarantine, and isolation (4 Apr 2020). Available at: https://www.cdc.gov/coronavirus/2019-ncov/prevent-getting-sick/social-distancing.html (accessed 17 May 2020).

12. Centers for Disease Control and Prevention. Community NPIs: Flu Prevention in Community Settings (26 Aug 2019). Available at: https://www.cdc.gov/nonpharmaceutical-interventions/community/index.html (accessed 18 May 2020).

13. Mahtani KR, Heneghan C, Aronson JK. What is the evidence for social distancing during global pandemics? A rapid summary of current knowledge. https://www.cebm.net/wp-content/uploads/2020/03/What-is-the-evidence-forsocial-distancing-during-global-pandemics-final-1.pdf (accessed 18 May 2020). 
